\title{
Composition and electronic structure of $\mathrm{Mn}_{3} \mathrm{O}_{4}$ and $\mathrm{Co}_{3} \mathrm{O}_{4}$ cathodes in zinc/air batteries: a DFT study
}

\author{
Fernanda Juarez and Hui Yin \\ Institute of Theoretical Chemistry, Ulm University, 89069 Ulm, Germany \\ Axel Groß* \\ Institute of Theoretical Chemistry, Ulm University, 89069 Ulm, Germany and \\ Helmholtz Institute Ulm (HIU), Electrochemical Energy Storage, 89069 Ulm, Germany
}

(Dated: November 16, 2021)

\begin{abstract}
The surface structures of promising cathode materials for zinc-air batteries, $\mathrm{Mn}_{3} \mathrm{O}_{4}$ and $\mathrm{Co}_{3} \mathrm{O}_{4}$, have been systematically studied under operating conditions by density functional theory calculations. The environment has been taken into account using grand-canonical schemes both for gas-phase and electrochemical conditions. By analysing the structures appearing in the calculated phase diagrams and Pourbaix diagrams in detail, we derive the factors underlying their stability in the gas phase and under electrochemical conditions. Changes in charge, oxidation states and spin states of the metal cations on the surface are discussed and their feasibility as active centers for the oxygen evolution and reduction reaction is thoroughly analyzed.
\end{abstract}

\section{INTRODUCTION}

In search for concepts to develop the next generation of batteries with comparable or even superior performances than existing devices, zinc-air batteries (ZABs) belong to the most promising approaches [1-3]. However, in spite of the many advantageous features, one of the basic problems for its use is the slow kinetics of oxygen evolution and reduction reactions (OER and ORR) on the air cathodes [1]. In recent years, many efforts have been devoted to solve this problem by finding new electrocatalysts with sufficiently high activities to promote both reactions [2, 4-9].

Manganese and cobalt oxides are natural candidates to enhance OER and ORR because of their role in the water oxidation in many biological systems, their multiple oxidation states, natural abundance, and inexpensive costs $[6,10-12]$. Besides, as in the case of other transition metal oxides [13], their catalytic activity can be enhanced by doping or by introducing oxygen vacancies.

In recent studies of OER reaction mechanisms on cobalt oxides, surface Co ions have been proposed as the active site for OER [14-16]. According to these proposals, the oxidation state of cobalt increases during OER. As a result, the density and oxidation state of surface cobalt ions are critical for OER/ORR activity. When these reactions are catalyzed by manganese or cobalt oxides or (oxy)hydroxides, it involves oxidation states from +2 to +4 , with the cation species $\mathrm{M}^{3+}$ being the main active center [15-17]. In bulk oxides, the coordination geometry of manganese and cobalt ions is usually tetrahedral $\left(T_{d}\right)$ or octahedral $\left(O_{h}\right)$ resulting in high-spin state for both $\mathrm{Co}^{2+}$ and $\mathrm{Mn}^{2+}$ ions (with magnetic moments $\mathrm{M} S$ of 3 and $5 \mu_{B}$, respectively). In contrast, for $\mathrm{Co}^{3+}$ three different spin states are possible, i.e. low-spin

\footnotetext{
* axel.gross@uni-ulm.de
}

$\left(M_{S}=0 \mu_{B}\right)$, high-spin $\left(M_{S}=4 \mu_{B}\right)$, and intermediate spin $\left(M_{S}=2 \mu_{B}\right)$. In this case the spin state is very sensitive to changes in the coordination geometry, e.g., $\mathrm{Co}-\mathrm{O}$ length or $\mathrm{Co}-\mathrm{O}-\mathrm{Co}$ angle. Different to the cobalt, in manganese oxides $\mathrm{Mn}^{3+}$ always remains in high-spin state $\left(M_{S}=4 \mu_{B}\right)[18]$.

In many transition metal oxides, when $\mathrm{Co}^{3+}$ is in the intermediate spin state, it has the electronic configuration: $t_{2 g}^{5} e_{g}^{1}$, whereas $\mathrm{Mn}^{3+}$ is in the $t_{2 g}^{3} e_{g}^{1}$ state [18-20]. Constructing catalysts with moderate binding strength between the active sites and reactants/intermediates, by optimizing the electronic configuration is an effective strategy to improve their electrocatalytic OER/ORR performance. The presence of a single electron in the anti-bonding $e_{g}$ orbital is expected to yield just the appropriate strength of interaction between $\mathrm{O}_{2}$ and the catalyst required for high OER and ORR activity and it is therefore considered to play a crucial role in the catalytic properties of the oxides [18-20].

Nevertheless, the reductive capacity of the metal ions in the oxide is not completely determined by the oxidation and spin states, the local geometry and coordination also play an important role. It is well-known that there are significant differences in catalytic activities between tetrahedrally and octahedrally coordinated sites [21]. In the work of Wang et al. [22], it was demonstrated that not only do the $\mathrm{Co}_{O_{h}}^{3+}$ species act as the active sites but also the $\mathrm{Co}_{O_{h}}^{2+}$ sites exhibit high catalytic activity due to the fact that they are easily oxidized to active $\mathrm{Co}^{3+}$ species. On the contrary, the $\mathrm{Co}_{T_{d}}^{2+}$ species shows poor catalytic activity.

Recent studies have confirmed that controlling the the surface morphology is a promising way to improve OER and ORR activities on transition metal oxides [23-25]. For example, it has been shown that $\mathrm{Co}_{3} \mathrm{O}_{4}(111)$ surfaces exhibits higher activities than other surface terminatons, probably as a consequence of its higher Co ion density and higher reactivity toward water dissoci- 
ation [23]. In another work, the addition of nanocrystalline $\mathrm{CeO}_{2}$ to $\mathrm{Co}_{3} \mathrm{O}_{4}$ has modified the local geometry and therefore the electronic structure of the $\mathrm{Co}^{3+}$ surface species so that they can be more easily oxidized into the $\mathrm{Co}^{4+}$ state [26]. The presence of defects has also been used to enhance the electrocatalytic performance of oxides for OER [15]. For example, Gong's group designed core-shell $\mathrm{Mn}_{3} \mathrm{O}_{4} @ \mathrm{Mn}_{x} \mathrm{Co}_{3-x} \mathrm{O}_{4}$ oxide catalysts that were terminated with abundant edge sites which, due to their unsaturated coordination, facilitated the adsorption of $\mathrm{OH}$ in basic conditions [27].

The surface $\mathrm{Co}-\mathrm{OH}$ groups are the starting point of the water oxidation cycle and they can be transformed into $\mathrm{Co}^{4+}$ oxo sites and subsequently form hydroperoxide and other intermediates [28]. In recent publications it was found that the preferred structural motifs under OER conditions consist of di- $\mu$-oxo-bridged $\mathrm{Co}_{O_{h}}^{3+/ 4+}$ ions with a contracted $\mathrm{CoO}_{6}$ bonding environment, where $\mu_{2}-\mathrm{OH}$ bridges are created between two electronically coupled high-spin cobalt ions [28-30]. The formation of these motifs is independent of the initial cobalt coordination and oxidation state, explaining the higher catalytic activity of surfaces in which they are already formed before the OER.

There have been several theoretical studies addressing the properties of manganese and cobalt oxide surfaces and their OER and ORR activities [17, 31-35]. However, to the best of our knowledge, there are hardly any systematic studies addressing the thermodynamically stable surface structures of these oxides under operating conditions except for Ref. [36]. Therefore, in this work we will determine the most stable structures of $\mathrm{Mn}_{3} \mathrm{O}_{4}$ and $\mathrm{Co}_{3} \mathrm{O}_{4}$ (111) surfaces both in gas phase and udner electrochemical conditions. This study is motivated by the notion that such an investigation is in principle mandatory $[37,38]$, as the most active catalyst will be useless if it is not stable under operating conditions. The operating conditions will be taken into account employing grandcanonical approaches [39]. Based on the concepts of $\mathrm{Ab}$ Initio Thermodynamics [40] and the Computational Hydrogen Electrode (CHE) [41], we will obtain the equilibrium structures as a function of either the chemical potentials of oxygen and hydrogen or of the electrode potential and $\mathrm{pH}$. We will also analyze the changes in charge, oxidation, and spin states of metal cations on the surface and their feasibility as active center for OER and ORR.

\section{COMPUTATIONAL DETAILS}

$\mathrm{Ab}$ initio calculations were performed with the periodic density functional theory (DFT) code Vienna $a b$ initio simulation package (VASP) [42]. The exchange and correlation energy was calculated within the generalized gradient approximation (GGA) using the PerdewBurke-Ernzerhof (PBE) functional [43]. To include van der Waals forces we added the D3 correction as imple- mented by Grimme et al. [44-46]. The electron-core interaction was described with the projector augmented wave (PAW) method [47].

The electronic wave functions were expanded using a plane wave basis set with an energy cutoff of $500 \mathrm{eV}$ and $600 \mathrm{eV}$ for $\mathrm{Co}_{3} \mathrm{O}_{4}$ and $\mathrm{Mn}_{3} \mathrm{O}_{4}$, respectively. The DFT+U approach was introduced to treat the highly localized $\mathrm{Co}$ and $\mathrm{Mn} 3 d$ states in $\mathrm{Co}_{3} \mathrm{O}_{4}$ and $\mathrm{Mn}_{3} \mathrm{O}_{4}$, using parameters of $U-J=2.5$ and $3.0 \mathrm{eV}$, respectively. These parameters were obtained by optimizing the description of pure Co and $\mathrm{Mn}$ as well as of different types of bulk oxides, as described in Refs. [35, 48, 49].

All structures were relaxed until the residual forces on the free atoms were smaller than $0.02 \mathrm{eV} / \AA$. The bulk $\mathrm{Co}_{3} \mathrm{O}_{4}$ and $\mathrm{Mn}_{3} \mathrm{O}_{4}$ oxides were optimized using $k$-point meshes of $7 \times 7 \times 7$ and $6 \times 6 \times 4$, respectively, yielding lattice constants of $a=b=c=8.16 \AA$ \} for $\mathrm{Co}_{3} \mathrm{O}_{4}$ and $a=b=5.87 \AA$ and $c=9.60 \AA$ for $\mathrm{Mn}_{3} \mathrm{O}_{4}$. The most stable magnetic structure found by us for each oxide was in accordance with previous studies $[50,51]$.

The $\mathrm{Co}_{3} \mathrm{O}_{4}$ (111) surfaces were represented using $(2 \times 2)$ slabs $\left(11.54 \times 11.54 \AA^{2}\right)$ consisting of 11 layers, where the bottom 7 layers were kept fixed during the relaxations. The $\mathrm{Mn}_{3} \mathrm{O}_{4}$ (111) surfaces were constructed using $(1 \times 1)$ slabs $\left(8.30 \times 11.25 \AA^{2}\right)$ with a thickness of 17 layers, keeping the bottom 8 layers fixed during the geometry optimizations. For the slabs calculations of cobalt and manganese oxides, $k$-point meshes of $6 \times 6 \times 4$ and $5 \times 5 \times 1$ were used, respectively. In all the cases, 15 to $20 \AA$ of vacuum were added in $z$-direction and dipole corrections were applied for the asymmetric slabs.

To simulate the effect of the water in the electrochemical interface we used an implicit solvent model [52-54] and the permittivity of clean water $\left(80 \frac{A s}{V m}\right)$. Local electronic charges were derived using the Bader charge partition scheme [55] for both the spin components. The spin magnetic moment ${ }_{\mathrm{M}} S$ (also known as magnetization) was calculated as the difference between the number of valence electrons at each spin state. It is important not to confuse this magnetic moment with the effective spin-only magnetic moment, that can be measured experimentally.

In order to derive the thermodynamically stable surface structures under operating conditions, grandcanonical approaches $[39,56]$ have been employed which have been shown to reliably reproduce experimentally determined surfaces structures $[37,57]$. The stability of the surfaces in gas phase was examined by calculating the Gibbs energy of formation $\Delta \gamma^{G A S}$, according to the Ab Initio Thermodynamics formalism [40]. To simulate the effect of the electrode potential $U$ and $\mathrm{pH}$ in the solid/liquid interface, the Gibbs energy of formation in solution $\Delta \gamma^{A Q}$ was computed using the Computational Hydrogen Electrode (CHE) method [41] and following the same methodology successfully used in Refs. [58, 59]. All details and definitions concerning the energies of formation $\Delta G_{\text {form }}^{G A S / A Q}$ are given in the Supporting Information (SI). 


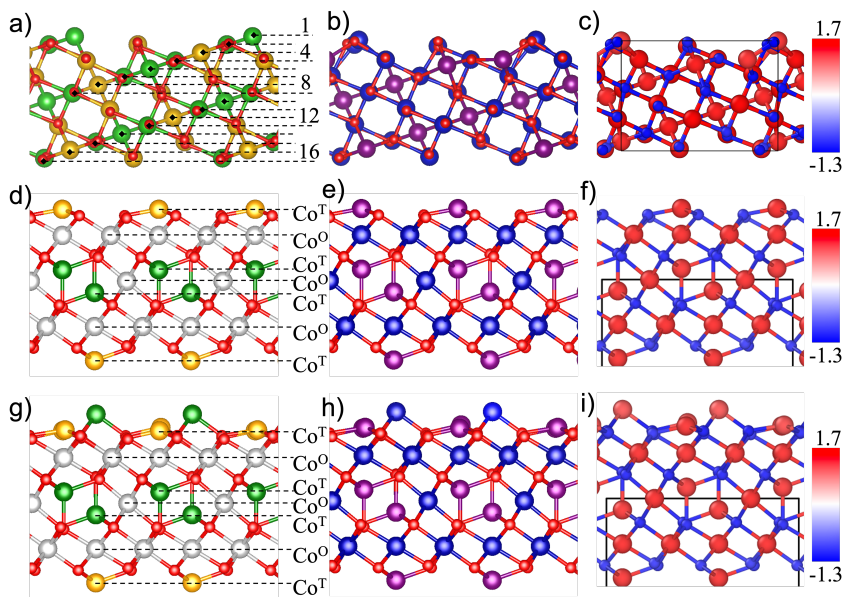

FIG. 1: Side view of $\mathrm{Co}_{3} \mathrm{O}_{4}$ and $\mathrm{Mn}_{3} \mathrm{O}_{4}$ (111) surfaces. The first row $(\mathrm{a}-\mathrm{c})$ represents the stoichiometric slab of manganese oxide, and the second and third rows $(\mathrm{d}-\mathrm{f}$,

and $g-i$ ) corresponds to the non-stoichiometric and stoichiometric slabs of cobalt oxide, respectively. In the first column ( $\mathrm{a}, \mathrm{d}$, and $\mathrm{g}$ ) the metal atoms were colored according to their magnetic moment: green

corresponding to spin up, yellow to spin down, and white to nearly zero. In the second column (b, e, and h) the metal atoms were painted in accordance with their coordination, where blue and purple corresponds to $\mathrm{M}_{O_{h}}$ and $\mathrm{M}_{T_{d}}$, respectively. In the last column (c, f, and $\mathrm{i}$ ) all the atoms were drawn in correspondence with

their charge and using the color scale on their sides.

\section{RESULTS}

\section{A. Formation energy of (111) surfaces in gas phase}

Although $\mathrm{Co}_{3} \mathrm{O}_{4}$ and $\mathrm{Mn}_{3} \mathrm{O}_{4}$ oxides have many similarities, the geometry of their (111) surfaces differs considerably. Both oxides are normal spinels with divalent and trivalent cations, located in tetrahedral and octahedral sites $\left(\mathrm{M}_{T_{d}}^{2+}\right.$ and $\left.\mathrm{M}_{O_{h}}^{3+}\right)$, respectively. However, whereas the cobalt oxide (II, III) has a cubic spinel structure, the manganese oxide (II, III) adopts a tetragonally distorted spinel structure known as hausmannite. This deformation along the [001] direction is the consequence of the Jahn-Teller effect on the coordination octahedron around the $\mathrm{Mn}^{3+}$ ions. The side views of the resulting (111) slabs are shown in Fig. 1.

The first row in Fig. 1 depicts the symmetric slab of the (111) surface of manganese oxide. This face has many possible terminations. To the best of our knowledge, it has not been systematically studied yet, so that the most stable structures had not been determined yet. Because of its asymmetric form, it is possible to cleave the bulk oxide in order to obtain stoichiometric slabs, as it is shown in Fig. 1. The resulting surface exposes many different type of $\mathrm{Mn}$ ions, with varying coordination and number of dangling bonds. Most of the ions on the surface of the
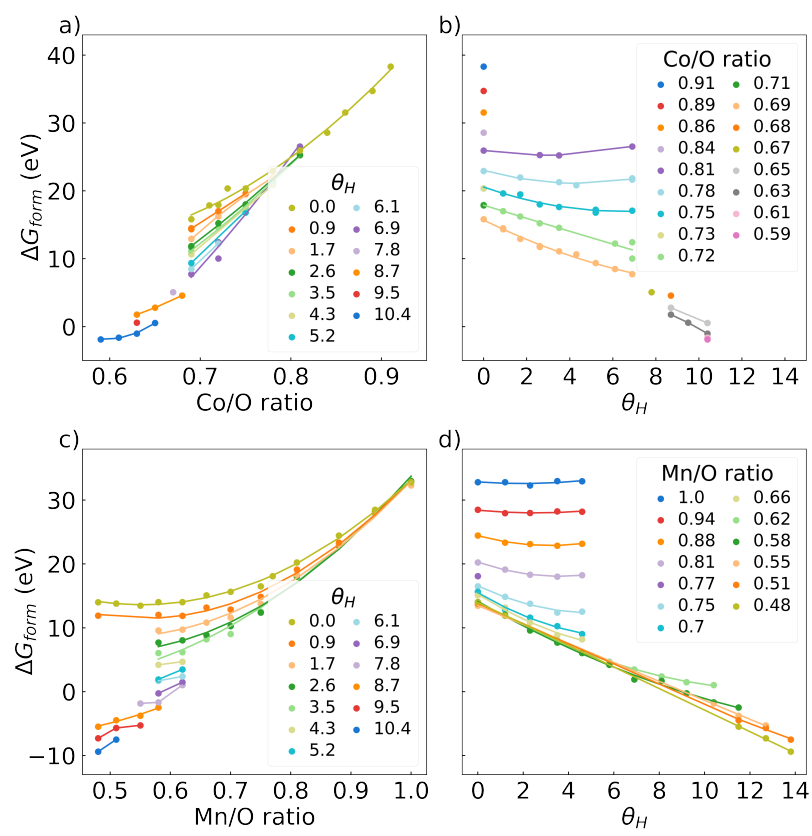

FIG. 2: Formation energy $\left(\triangle G_{\text {form }}^{G A S}\right)$ in gas phase of: (a, b) $\mathrm{Co}_{3} \mathrm{O}_{4}$ and (c, d) $\mathrm{Mn}_{3} \mathrm{O}_{4}$ (111) surfaces. The energies are plotted as a function of: $(a, c)$ the metal/oxygen ratio $n_{\mathrm{M}} / n_{\mathrm{O}}$ and $(\mathrm{b}, \mathrm{d})$ the amount of $\mathrm{H}$ per surface area $\theta_{\mathrm{H}}$.

slab belong to octahedral sites but a few tetrahedral ions are also accessible from the top. With the purpose of considering different $\mathrm{Mn} / \mathrm{O}$ proportions on the surface, we added manganese and/or oxygen atoms to this initial structure. The newly added atoms were placed in positions that maximize the number of $\mathrm{Mn}-\mathrm{O}$ bonds and reduce the number of dangling bonds.

The bulk $\mathrm{Co}_{3} \mathrm{O}_{4}$ oxide can be cleaved through six different planes in order to create unreconstructed (111) surfaces, two of which are terminated by oxygen atoms and the rest of them exposing different type of Co atoms [33]. However, none of the symmetric (1x1)-slabs recovers the stoichiometry of the bulk oxide. Previous studies, not including $\mathrm{H}$ adsorption, have shown that the most stable surface has a metal/oxygen ratio $n_{\mathrm{Co}} / n_{\mathrm{O}}$ close to 0.75 , and it is terminated by divalent cations $\mathrm{Co}_{T_{d}}^{2+}$ (see Fig. 1d-f) [34]. These cobalt ions are surrounded by three $\mathrm{O}$ atoms having one dangling bond. Starting from this $\mathrm{O}-$ rich surface it is possible to obtain an stoichiometric slab by partially covering it with Co ions. These cations occupy octahedral sites and are bound to the $\mathrm{O}$ atoms in the second layer, being less saturated than the Co ions in the first layer (see Fig. 1g-i). The stoichiometric termination of this surface is also an important structure that can be predominant when the chemical potential of the species is modified. Together with the non-stoichiometric O-rich terminations, they are the prevalent structures under experimental conditions, without considering the presence of hydrogen [34]. 
We started our study by first analyzing the stability of different slab terminations in gas phase using the formation energy $\Delta G_{\text {form }}^{G A S}$. Figure 2 shows this energy as a function of the proportion between metal and oxygen atoms $n_{\mathrm{M}} / n_{\mathrm{O}}$ and the amount of $\mathrm{H}$ per surface area $\theta_{\mathrm{H}}$. As far as $\mathrm{Mn}_{3} \mathrm{O}_{4}$ is concerned (see Fig. 2b), for low hydrogen content the minimum of the formation energy is close to to the stoichiometric ratio $n_{\mathrm{M}} / n_{\mathrm{O}}=0.75$. Increasing the amount of oxygen, i.e., going to lower $\mathrm{Mn} / \mathrm{O}$ rations, does not significantly modify the energy values, as this situation corresponds to the saturation of the initial dangling bonds of the metal ions. On the other hand, increasing the amount of metal ions leads to higher energies because, despite of creating new $\mathrm{M}-\mathrm{O}$ bonds, new dangling bonds are being formed on the surface.

The relationship between the formation energy and the amount of hydrogen on the surface depends on the $n_{\mathrm{M}} / n_{\mathrm{O}}$ ratio (see Fig. $2 \mathrm{~b}$ and $\mathrm{d}$ ). In general, a smooth transition between two limiting situations can be observed. On the one hand, the energy remains practically constant upon the addition of hydrogen to the surface when the $n_{\mathrm{M}} / n_{\mathrm{O}}$ ratio is high. This is due to a competition between the metal ions and the hydrogen atoms for the most reactive oxygen sites. In some cases the coordination of the metal ions on the top is being reduced in order to form new $\mathrm{O}-\mathrm{H}$ bonds. On the other hand, the formation energy decreases almost linearly with the amount of $\mathrm{H}$ when the surface has a higher content of oxygen.

As we already pointed out, the structure of (111) surface of manganese oxide is very different to the cobalt oxide. In the former case, it is possible to saturate each oxygen atom exposed at the surface with one hydrogen atom without increasing the energy of the slab. On the cobalt oxide surface, only half of the oxygen atoms that belong to the second layer of the original slab (Fig. 1d-f) can be bound to hydrogen. In the presence of a solvent, the repulsion between hydrogen atoms that are adsorbed on first neighbors oxygen ions and separated by $2.08 \AA$, rises from $0.2 \mathrm{eV}$ to $1.0 \mathrm{eV}$ upon increasing the number of first neighbors from one to two. Nevertheless, all the newly adsorbed $\mathrm{O}$ atoms can be saturated with $\mathrm{H}$ atoms to create hydroxyl groups.

\section{B. Phase diagrams in gas phase}

In spite of having found that fully hydroxylated surfaces have the lowest Gibbs energy of formation, the chemical composition of the (111) surfaces depends on the external conditions to which it is exposed, e.g. temperature, partial pressure of oxygen, hydrogen, etc. The most stable systems are shown in Figs. 3 and 4 for $\mathrm{Co}_{3} \mathrm{O}_{4}$ and $\mathrm{Mn}_{3} \mathrm{O}_{4}$, respectively. In order to make it easier to characterize the stable phases, we collect the most important parameters in Table I. Side and top views are included of the stable surfaces phases are shown in the SI.

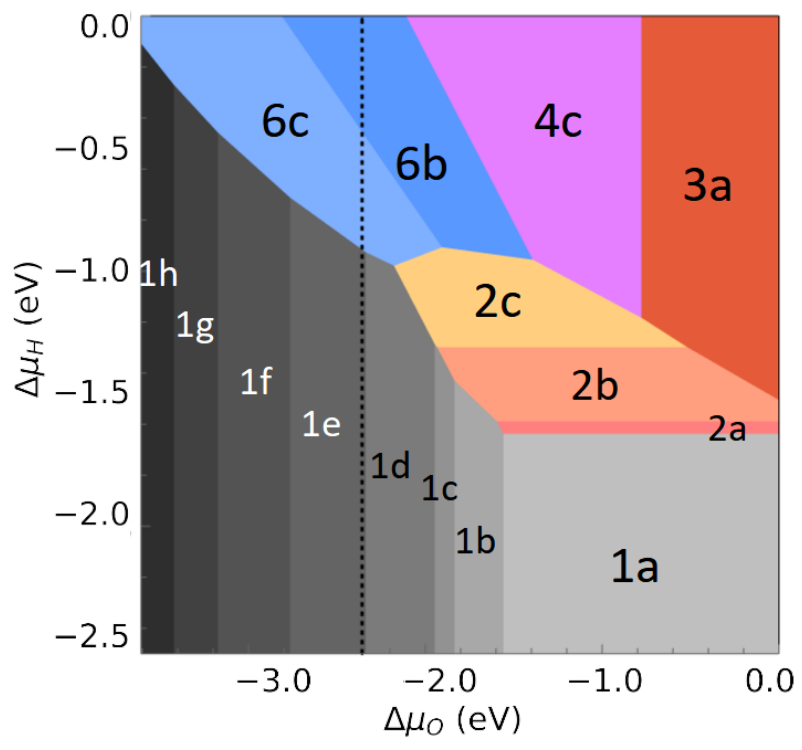

FIG. 3: Phase diagram in gas phase of the (111) surface of $\mathrm{Co}_{3} \mathrm{O}_{4}$. The dashed black line indicates the dissolution of the bulk oxide, hence the lower limit of

$\mu_{\mathrm{O}}$.

The system labels in the phase diagrams are organized as follows. Surface terminations without any hydrogen are plotted with shades of grey and they are numbered starting from 1 on both phase diagrams. The O-rich and the stoichiometric $\mathrm{Co}_{3} \mathrm{O}_{4}$ (111) surfaces are, respectively, labeled as $\mathbf{1 a}$ and 1c in Fig. 3. All the systems labeled with $\mathbf{1}$ have a higher metal to oxygen ratio as $\Delta \mu_{\mathrm{O}}$ decreases. The stoichiometric surface of the manganese oxide corresponds to system 1a in Fig. 4.

On the manganese oxide, the systems that contain hydrogen are predominantly numbered according to the ratio $n_{\mathrm{Mn}} / n_{\mathrm{O}}$, for instance systems $\mathbf{5 a}$ and $\mathbf{5} \mathbf{b}$ have the same amount of $\mathrm{Mn}$ and $\mathrm{O}$ but they differ in the content of H. Increasing numbers were used to indicate a higher proportion of oxygen on the surface. The surfaces denoted by 7 require special attention. They correspond to surfaces with varying low metal to oxygen ratios and a maximum number of adsorbed $\mathrm{H}$ on the $\mathrm{O}$ atoms.

The cobalt oxide surfaces containing $\mathrm{H}$ atoms are mainly organized according to the number of metal ions on top of the slab $n_{\mathrm{Co}}$. Systems starting with $\mathbf{2}$ and $\mathbf{3}$ have the same amount of metal and oxygen than system 1a. The family of systems $\mathbf{3}$ was created by adding more $\mathrm{OH}$ groups to system 2d. Finally, the group of slabs labeled by $\mathbf{4}, \mathbf{5}$, and $\mathbf{6}$ have an increasingly amount of cobalt ions.

Naturally, the systems with the lowest energy of formation $\Delta G_{\text {form }}^{G A S}$ are the thermodynamically stable ones for chemical potentials of $\Delta \mu_{\mathrm{H}}=\Delta \mu_{\mathrm{O}}=0$. But as soon as the chemical potentials start to deviate from zero, the stability changes. In both oxides, when the partial pressure of hydrogen is low corresponding to small chemical 


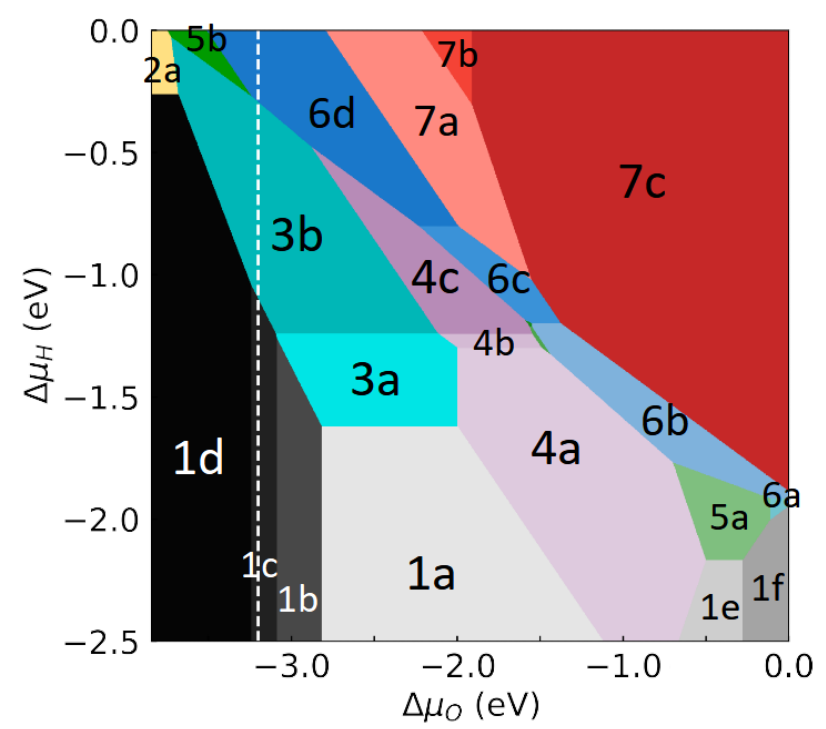

FIG. 4: Phase diagram in gas phase of the (111) surface of $\mathrm{Mn}_{3} \mathrm{O}_{4}$. The dashed white line indicates the dissolution of the bulk oxide, hence the lower limit of $\mu_{\mathrm{O}}$.

potentials, the stable surfaces are not covered by any hydrogen adsorbates. This group of systems then has a chemical composition that purely depends on the chemical potential of $\mathrm{O}$ for very low hydrogen chemical potentials, in particular for $\mathrm{Co}_{3} \mathrm{O}_{4}$.

Note that the variety of different stable terminations of the $\mathrm{Mn}_{3} \mathrm{O}_{4}$ (111) surface is larger than those of the $\mathrm{Co}_{3} \mathrm{O}_{4}$ surface. This is also the result of the peculiar structure of the (111) face of the hausmannite crystal. Nevertheless, most of the stable systems have the same amount of manganese exposed to the surface $\theta_{\mathrm{M}}=5.9$, typically higher than in the cobalt oxide case. Different rations $n_{\mathrm{Mn}} / n_{\mathrm{O}}$ are obtained by adding or removing $\mathrm{O}$ atoms. Each chemical composition of the surface is stabilized by hydroxylating the maximum amount of superficial $\mathrm{O}$ with additional $\mathrm{H}$. As a consequence, the stable systems shown in Fig. 4 acquire a higher number of $\mathrm{H}$ on the surface as the ratio $n_{\mathrm{M}} / n_{\mathrm{O}}$ decreases.

With the addition of hydrogen atoms to the surface, the stable systems shown in the phase diagram of $\mathrm{Co}_{3} \mathrm{O}_{4}$ have a chemical composition that becomes closer to the one of bulk oxide. The ratio $n_{\mathrm{Co}} / n_{\mathrm{O}}$ is slightly lower than 0.75 but still between 0.69 and 0.72 . The group of systems labeled with 2 represents the initial stages of the hydrogenation of the O-rich surface labeled as $\mathbf{1 a}$. All the other stable terminations have higher amounts of metal atoms which is being compensated by the addition of oxygen and hydrogen atoms forming $\mathrm{OH}$ groups.

In general, we find that there is a good agreement between the results shown in Fig. 3 and those presented in Ref. [36]. The same structures are present at low $\mathrm{H}$ and $\mathrm{O}$ chemical potentials, however, the results differ at higher potential because in Ref. [36] the adsorption of water molecules was also considered. Another minor source for variation is the difference in the reference energy of the $\mathrm{O}_{2}$ molecule which we derived from the formation energy of water.

\section{Phase diagrams in the presence of an aqueous electrolyte}

Figures 5 and 6 show the phase diagrams of the $\mathrm{Co}_{3} \mathrm{O}_{4}$ and $\mathrm{Mn}_{3} \mathrm{O}_{4}(111)$ surfaces in the presence of an aqueous

TABLE I: Description of the structures shown in the phase and Pourbaix diagrams, using as parameters the ratio of metal to oxygen atoms (in the surface): $n_{\mathrm{M}} / n_{\mathrm{O}}$, and the amount of metal and hydrogen atoms per surface area: $\theta_{\mathrm{M}}$ and $\theta_{\mathrm{H}}$, respectively. Pictures are included in the SI (Figs. S1-S6).

(a) $\mathrm{Co}_{3} \mathrm{O}_{4}$ (111) surface

\begin{tabular}{|c|c|c|c|}
\hline System & $\boldsymbol{n}_{\mathbf{M}} / \boldsymbol{n}_{\mathbf{O}}$ & $\mathbf{1 0}^{\mathbf{2}} \boldsymbol{\theta}_{\mathbf{M}}^{\boldsymbol{S}} / \AA^{2}$ & $\mathbf{1 0}^{\mathbf{2}} \boldsymbol{\theta}_{\mathbf{H}} / \AA^{2}$ \\
\hline $\mathbf{1 a}$ & 0.69 & 3.5 & \\
$\mathbf{1 b}$ & 0.72 & 4.3 & \\
$\mathbf{1 c}$ & 0.75 & 5.2 & \\
$\mathbf{1 d}$ & 0.78 & 6.1 & 0 \\
$\mathbf{1 e}$ & 0.81 & & \\
$\mathbf{1 f}$ & 0.84 & 6.9 & \\
$\mathbf{1 g}$ & 0.86 & & \\
$\mathbf{1 h}$ & 0.89 & & 0.9 \\
$\mathbf{2 a}$ & & & 1.7 \\
$\mathbf{2 b}$ & 0.69 & 3.5 & 2.6 \\
$\mathbf{2 c}$ & & & 10.4 \\
$\mathbf{3 a}$ & 0.61 & 3.5 & 8.7 \\
\cline { 2 - 4 } $\mathbf{4 c}$ & 0.63 & 5.2 & 6.9 \\
\cline { 2 - 3 } $\mathbf{6 b}$ & 0.68 & 6.9 & \\
$\mathbf{6 c}$ & 0.72 & & \\
\hline
\end{tabular}

(b) $\mathrm{Mn}_{3} \mathrm{O}_{4}$ (111) surface

\begin{tabular}{|c|c|c|c|}
\hline System & $n_{\mathrm{M}} / n_{\mathrm{O}}$ & $10^{2} \theta_{M}^{S} / \AA^{2}$ & $10^{2} \theta_{\mathrm{H}} / \AA^{2}$ \\
\hline $1 a$ & 0.75 & 6.9 & \multirow{6}{*}{ 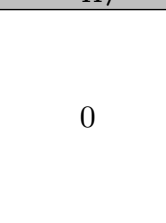 } \\
\hline $1 b$ & 0.81 & 8.1 & \\
\hline 1c & 0.94 & 10.4 & \\
\hline 1d & 1.00 & 11.5 & \\
\hline $1 e$ & 0.62 & \multirow{2}{*}{6.9} & \\
\hline 1f & 0.55 & & \\
\hline $2 \mathbf{a}$ & 1.00 & 11.5 & 2.3 \\
\hline $3 \mathbf{a}$ & \multirow{2}{*}{0.75} & \multirow{14}{*}{6.9} & 1.2 \\
\hline $3 b$ & & & 2.3 \\
\hline $4 a$ & \multirow{3}{*}{0.71} & & 1.2 \\
\hline $4 \mathrm{~b}$ & & & 3.5 \\
\hline $4 \mathrm{c}$ & & & 4.6 \\
\hline $5 a$ & \multirow{2}{*}{0.62} & & 2.3 \\
\hline $5 b$ & & & 10.4 \\
\hline $6 a$ & \multirow{4}{*}{0.58} & & 2.3 \\
\hline $6 \mathrm{~b}$ & & & 6.9 \\
\hline $6 c$ & & & 10.4 \\
\hline $6 d$ & & & 11.5 \\
\hline $7 a$ & \multirow{3}{*}{$\begin{array}{l}0.55 \\
0.51 \\
0.48\end{array}$} & & 12.7 \\
\hline $7 \mathrm{~b}$ & & & \multirow{2}{*}{13.8} \\
\hline $7 \mathrm{c}$ & & & \\
\hline
\end{tabular}



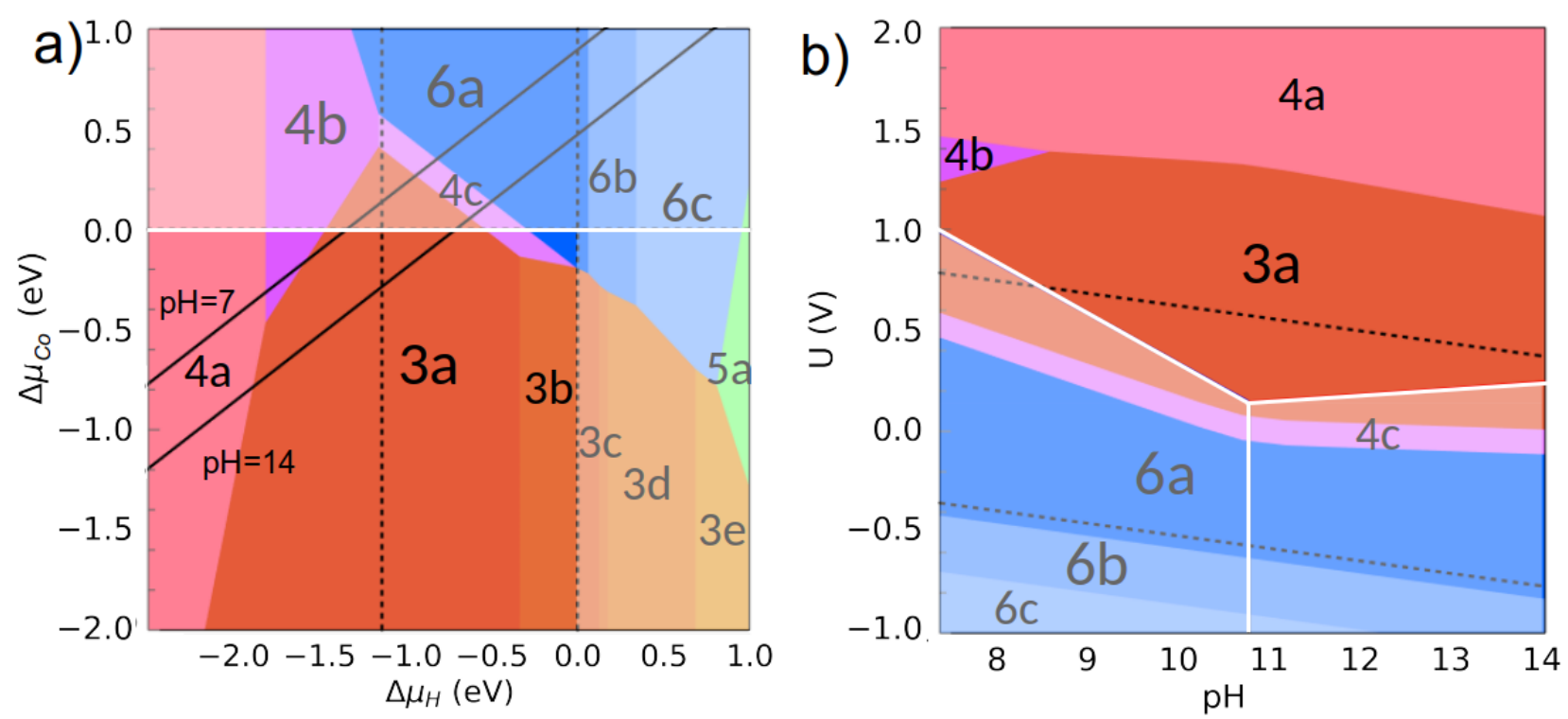

FIG. 5: (a) Phase and (b) Pourbaix diagrams of the $\mathrm{Co}_{3} \mathrm{O}_{4}(111)$ surface in solution. The dashed black line indicates the evolution of $\mathrm{O}_{2}$ and $\mathrm{H}_{2}$ from water, therefore the lower and upper limits of $\mu_{\mathrm{H}}$, respectively. The white lines indicates the regions of stability of the metal ions in its acidic and alkaline forms. The black lines on the left plot correspond to constant $\mathrm{pH}$ values of 7 and 14. The Pourbaix diagrams were calculated for room temperature $(T=298.15 K)$, and a molar Co concentration $[M]=10^{-6} \mathrm{M}$ in the aqueous electrolyte.
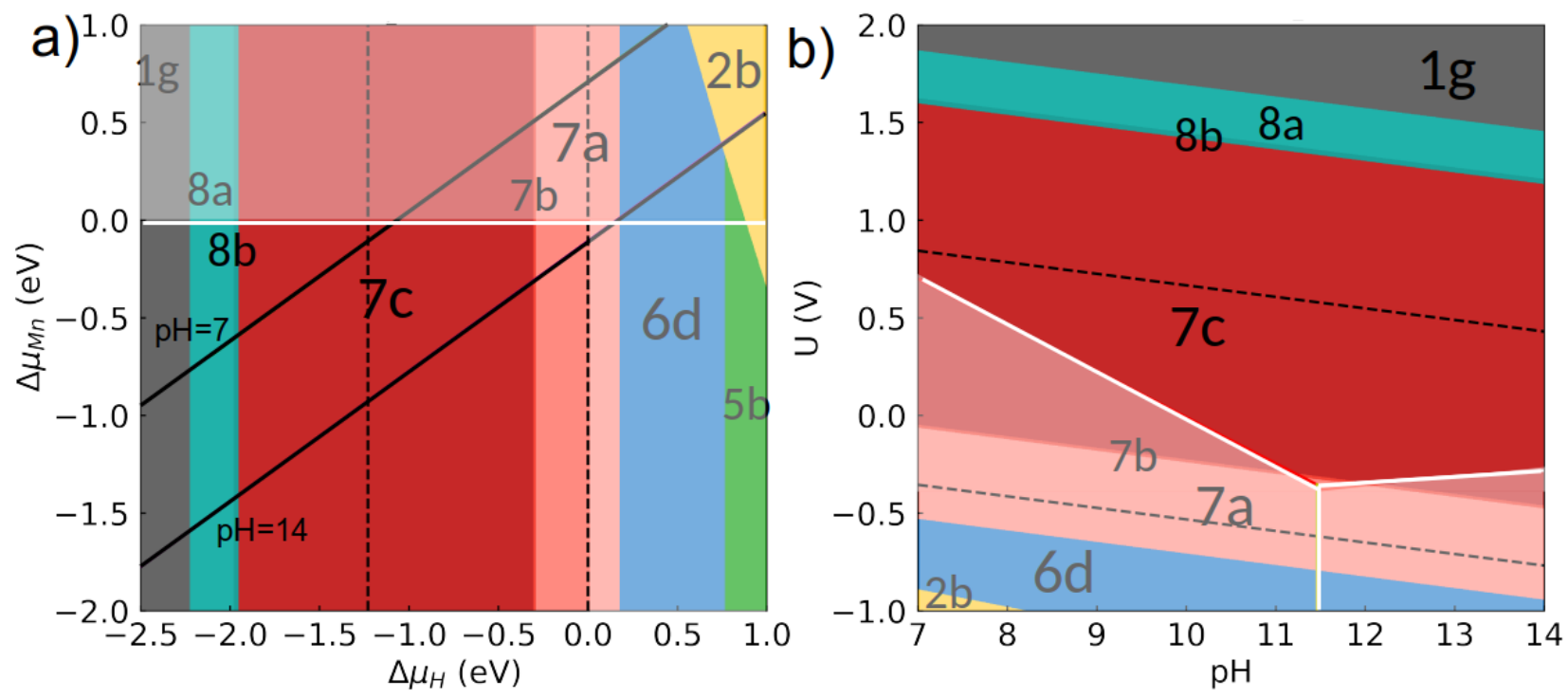

FIG. 6: (a) Phase and (b) Pourbaix diagrams of the $\mathrm{Mn}_{3} \mathrm{O}_{4}(111)$ surface in solution. The dashed black line indicates the evolution of $\mathrm{O}_{2}$ and $\mathrm{H}_{2}$ from water, therefore the lower and upper limits of $\mu_{\mathrm{H}}$, respectively. The white lines indicates the regions of stability of the metal ions in its acidic and alkaline forms. The black lines on the left plot correspond to constant $\mathrm{pH}$ values of 7 and 14. The Pourbaix diagrams were calculated for room temperature $(T=298.15 K)$, and and a molar Mn concentration $[M]=10^{-6} \mathrm{M}$ in the aqueous electrolyte.

electrolyte, plotted as a function of the electrochemical potentials of the hydrogen and metal ions, $\tilde{\mu}_{\mathrm{H}^{+}}$and $\tilde{\mu}_{\mathrm{M}}$ respectively. Here we have also added different lines that represent the limits of the stability of the resources. For hydrogen, the stability window is given by the dissolution of water to form $\mathrm{O}_{2}$ or $\mathrm{H}_{2}$ molecules (black dashed lines). In the potential region that we have studied these systems, the bulk oxide can be dissolved into the acidic 

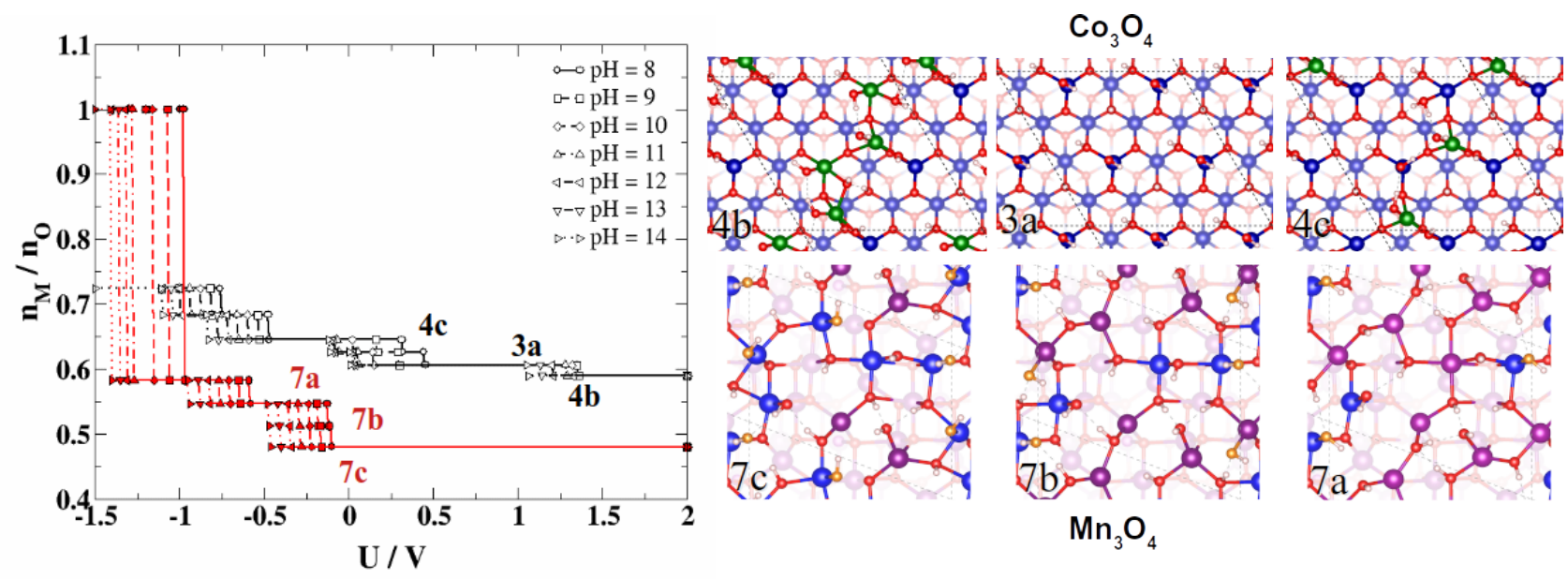

FIG. 7: Ratio of number of metal to oxygen atoms $n_{\mathrm{M}} / n_{\mathrm{O}}$ in the (111) surfaces of $\mathrm{Mn}_{3} \mathrm{O}_{4}$ (red symbols) and $\mathrm{Co}_{3} \mathrm{O}_{4}$ (black symbols) as a function of the electrode potential $U$ and the $\mathrm{pH}$. Additional top views of the most important surface terminations were added on the side. The supercells of $\mathrm{Co}_{3} \mathrm{O}_{4}$ and $\mathrm{Mn}_{3} \mathrm{O}_{4}$ have an area of: $11.54 \times 11.54 \AA^{2}$, and $8.30 \times 11.25 \AA^{2}$, respectively. $\mathrm{Mn}^{2+}, \mathrm{Mn}^{3+}, \mathrm{Co}^{2+}, \mathrm{Co}^{3+}, \mathrm{O}$ and $\mathrm{H}$ are represented as purple, blue, navy blue, green, red, and white spheres, respectively.

or the alkaline form of the $\mathrm{M}^{2+}$ ion, leading to the upper limit of its electrochemical potential. Before going further, we want to stress the fact that all our results are only strictly valid for thermodynamic equilibrium conditions, kinetic effects are not taken into account which might of course alter the results. This particularly concerns the stability of the phases at a boundary between two phases.

It also needs to noted that some regions in the phase diagram are not reachable because the $\mathrm{pH}$ is beyond experimental conditions. Note first that the electrochemical potentials of the protons and of the metal cations $\mathrm{M}^{2+}$ are not independent of each other (see Eq. S6). Furthermore, by combining the expressions for these electrochemical potentials Eqs. 5 and 8, we can eliminate the electrode potential in the relation between $\Delta \tilde{\mu}_{\mathrm{M}^{2+}}$ and $\Delta \tilde{\mu}_{\mathrm{H}^{+}}$(see Eq. S8), which allows as to determine the range of feasible alkaline $\mathrm{pH}$ values between 7 and 14 which are included as two black lines in Figs. 5a and 6a. In order to understand the chemistry of the surfaces, we extended the plots beyond all the proposed limits. Again, the parameters characterizing the stable systems are given Table I, and side and top views of the atomistic structures of the phases can be found in the SI, Figs. S1S6. Furthermore, the degree of oxidation of the surface as a function of the electrode potential and $\mathrm{pH}$ is shown in Fig. 7, where also additional top views of the most important terminations in or close to the stability regions are provided.

In order to be able to better read the phase diagrams of $\mathrm{Co}_{3} \mathrm{O}_{4}$ and $\mathrm{Mn}_{3} \mathrm{O}_{4}$ in the presence of an aqueous electrolyte, we emphasize certain characteristics related to the arrangement of the stable phases which can all be derived from the particular expressions of the electrochemical potentials given in the SI. Note that systems that have the same number of metal ions per surface area are separated by a vertical line, parallel to the $\Delta \tilde{\mu}_{M}$ axis. A negative slope of the line that separates two systems indicates that the slab on the right side has a higher concentration of metal ions than the other one. The second related feature is that surfaces that are stable in regions of higher $\Delta \tilde{\mu}_{\mathrm{M}}$ values have a higher content of metal ions. Furthermore, stable systems are arranged in order of increasing $n_{\mathrm{M}} / n_{\mathrm{O}}$ ratio as $\Delta \tilde{\mu}_{\mathrm{H}^{+}}$becomes more positive. In the particular cases when several surfaces have the same $n_{\mathrm{M}} / n_{\mathrm{O}}$ ratio, the slabs with higher amount of $\mathrm{H}$ are placed in regions of higher $\Delta \tilde{\mu}_{\mathrm{H}^{+}}$.

In contrast to the gas phase, at the electrolyte/electrode interface it is very unlikely to have any termination of the $\mathrm{Co}_{3} \mathrm{O}_{4}$ or $\mathrm{Mn}_{3} \mathrm{O}_{4}$ (111) surfaces in the absence of any amount of adsorbed hydrogen. Actually, most of the systems are highly hydrogenated (see Figs. S1-S6).

As Fig. 7 indicates, the variation of the $n_{\mathrm{M}} / n_{\mathrm{O}}$ ratio is rather small, with a higher oxidation of the metal ions in the manganese oxide surfaces. This plot also demonstrates that our model correctly reproduces the increasing oxidation of the surface as the electrode potential $U$ increases. It can also be noticed that the most stable systems (3a for $\mathrm{Co}_{3} \mathrm{O}_{4}$ and $\mathbf{7} \mathbf{c}$ for $\mathrm{Mn}_{3} \mathrm{O}_{4}$, respectively) are the result of the tendency to maximize the hydroxylation of the surface. These stable systems have the lowest possible $n_{\mathrm{M}} / n_{\mathrm{O}}$ proportion that allows to have the maximum amount of adsorbed hydrogen and, if possible, the lowest number of metal ions exposed on the surface (see the minimum in Fig. S7c). 


\section{Geometry and electronic structure of $\mathrm{Mn}_{3} \mathrm{O}_{4}(\mathbf{1 1 1})$ surface in solution}

The Pourbaix diagrams illustrate the change in the stability of different surface terminations as a function of electrochemical control parameters. At the same time, their structures also determines the catalytic processes that can occur on them. However, a deeper analysis is required to understand how locally any reactions can proceed. It is beyond the scope of the present paper to perform a detailed study of OER and ORR reaction mechanisms by calculating the energies of reaction intermediates and deriving reaction paths. Still, we want to assess the potential catalytic activity of the resulting surface structures by analysing their geometric and electronic properties in some detail. On the $\mathrm{Mn}_{3} \mathrm{O}_{4}(111)$ surface, we have analyzed the metal ions of the four systems $\mathbf{6 d}$, $\mathbf{7 a}, \mathbf{7 b}$, and $\mathbf{7 c}$ that belonged to the seven topmost layers in the unrelaxed and non-hydrogenated surface structures. Note that these the four considered systems are the stable phases in the Pourbaix diagram Fig. 6 arranged according to increasing electrode potentials. The last three structures $\mathbf{7 a}, \mathbf{7 b}$, and $\mathbf{7 c}$ are the most stable ones in the region of thermodynamic stability, the first one is a more reduced surface termination, according to our phase diagrams (Fig. 6). Figure 8 collects the magnetic moment, charge, and coordination of these atoms.
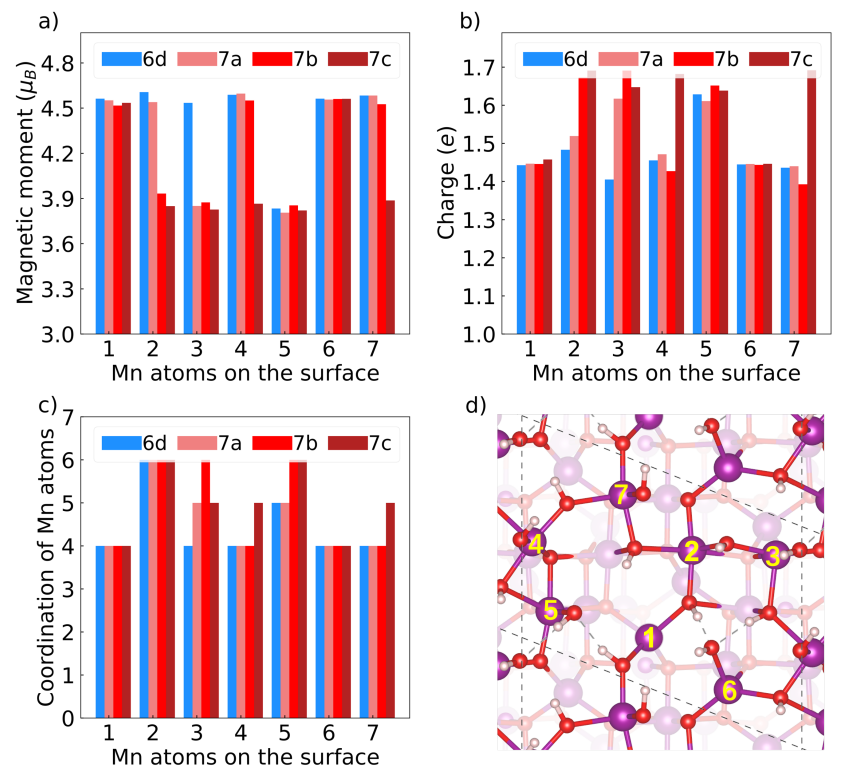

FIG. 8: Magnetic moment, charge, and coordination of the topmost metal atoms on the most stable (111) surfaces of $\mathrm{Mn}_{3} \mathrm{O}_{4}$. A top view of system $\mathbf{7 c}$ with the atoms labeled as in the charts has also been included.

Typically, in the bulk $\mathrm{Mn}_{3} \mathrm{O}_{4}$ oxide there are only two types of metal ions: tetrahedrally coordinated $\mathrm{Mn}^{2+}$ ions and $\mathrm{Mn}^{3+}$ cations with octahedral coordination. According to our calculations and in very good agreement with previous DFT results [60], the charge and magnetic mo- ment in the bulk are $+1.51 e / 4.5 \mu_{B}$ and $+1.64 e / 3.8 \mu_{B}$ for $\mathrm{Mn}^{2+}$ and $\mathrm{Mn}^{3+}$, respectively. In Fig. 8, it can be clearly observed that the oxidation state of the atoms changes from +2 to +3 for several atoms as the electrode potential increases, i.e., for more oxidizing conditions, whereas the coordination oscillates between tetrahedral and an octahedral geometries. There is a good correlation between the magnetic moment and the charge in these atoms (see Fig. 9) with a charge value of $+1.55 e$ separating oxidation states +2 and +3 . From both figures it is evident that the magnetic moment is a better indicator of the oxidation state of the ions than the Bader charge.

According to Fig. 8, the feasibility of oxidating the metal ions on the surface is as follows: $5>3>2>$ $4,7>1,6$. Atom 5 always stays in oxidation state III, and atoms 1 and 6 remain as $\mathrm{Mn}^{2+}$, even in structure $\mathbf{7 c}$, i.e., at high potentials.

From the seven selected ions, atom number 1 is the deepest one and it is the only one that, even in the stoichiometric clean surface, is completely coordinated. In the cases that we analyzed, this atom neither changes its oxidation state $(+2)$ nor its tetrahedral coordination, probably because of steric hindrance. Similarly, atom 6 always remains in oxidation state +2 , coordinated by four neighbors. This atom is more exposed to the surface than atom 1 but as a result of the surface cleavage, it is contracted inwards, creating stronger bonds and becoming more inactive to oxidation.

Atom 2 corresponds to an interesting case. In most cases, the oxidation is a consequence of the adsorption of new $\mathrm{O}$ atoms (or $\mathrm{OH}$ groups). Upon increased oxidation, this atom never changes the number of neighbors, having always an octahedral coordination. Nevertheless its oxidation state goes from +2 to +3 because the charge in the ion locally changes as the result of the oxidation of its neighbor (atom 3).

Among the considered atoms, atoms 4 and 7 are probably the most active towards the OER. As stated in the Introduction, these atoms fulfill two of the criteria for a good catalyst for this reaction: an oxidation state +3 and an incomplete coordination sphere. Because both
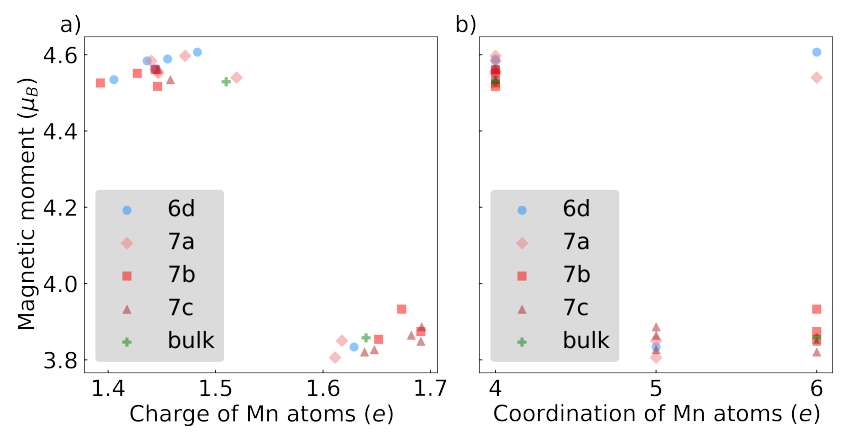

FIG. 9: Magnetic moment of the topmost metal atoms on the most stable $\mathrm{Mn}_{3} \mathrm{O}_{4}(111)$ surfaces as a function of its charge and coordination. 


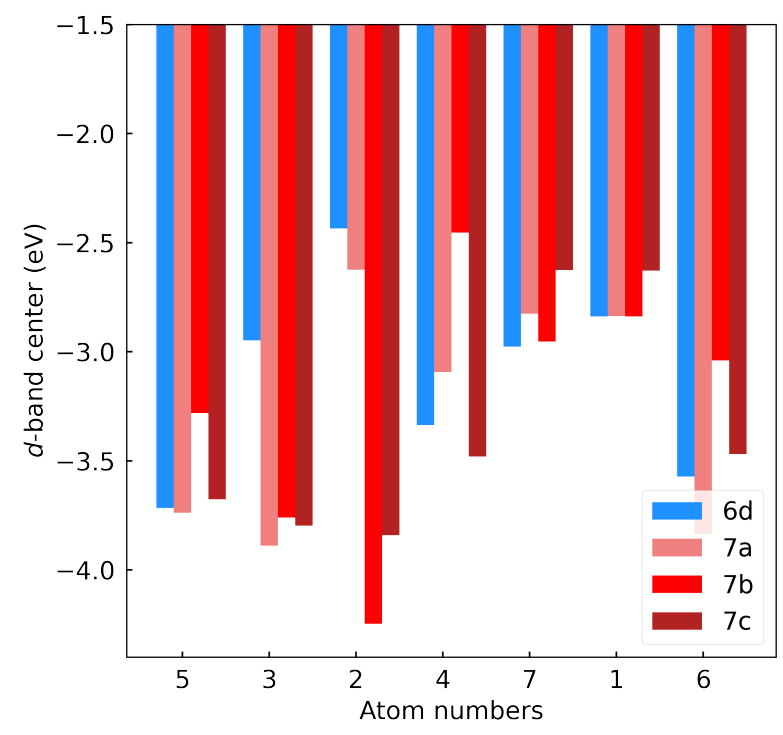

FIG. 10: Center of the d-band of the topmost metal atoms on the most stable (111) surfaces of $\mathrm{Mn}_{3} \mathrm{O}_{4}$.

of them are in the topmost position and not completely coordinated, they are easier to access by any reactant approaching the surface. Furthermore, atoms 4 and 7 are connected through a $\mu_{2}-\mathrm{OH}$ bridge, making this $\mathrm{H}$ atom the most acidic site and likely to be deprotonated.

Another descriptor that it is extensively used in the field of electrocatalysis is the position of the center of the d-band. In this case there is not a direct correlation between the position of the d-band and the magnetic moment of the manganese ions. Nevertheless it can be observed that in most the atoms in Figure 10 the oxidation process shifts the d-band center deeper in energy. In the most stable surface (7c) only atoms 1 and 7 have d electrons closer to the Fermi level and hence easier to take by any oxidizing agent. Because of the reasons mentioned before, atom 7 can be easily reached and oxidized for any adsorbant on the surface whereas atom 1 can only be indirectly oxidized.

\section{E. Geometry and electronic structure of $\mathrm{Co}_{3} \mathrm{O}_{4}(111)$ surface in solution}

The amount of metal ions on the surfaces of the most stable terminations of $\mathrm{Co}_{3} \mathrm{O}_{4}(111)$ is different. The most reduced systems, $\mathbf{6} \mathbf{b}$ and $\mathbf{6 a}$, have a higher amount of ions on the surface, whereas the more oxidized surface 3a has a lower amount. Hence, the oxidation states can not be followed atom by atom.

The magnetic moment and the Bader charges of all the atoms on the stable systems: $\mathbf{4 b}, \mathbf{3} \mathbf{a}$, and $\mathbf{4} \mathbf{c}$, and on the more reduced surfaces: $\mathbf{6} \mathbf{a}$ and $\mathbf{6} \mathbf{b}$, are collected
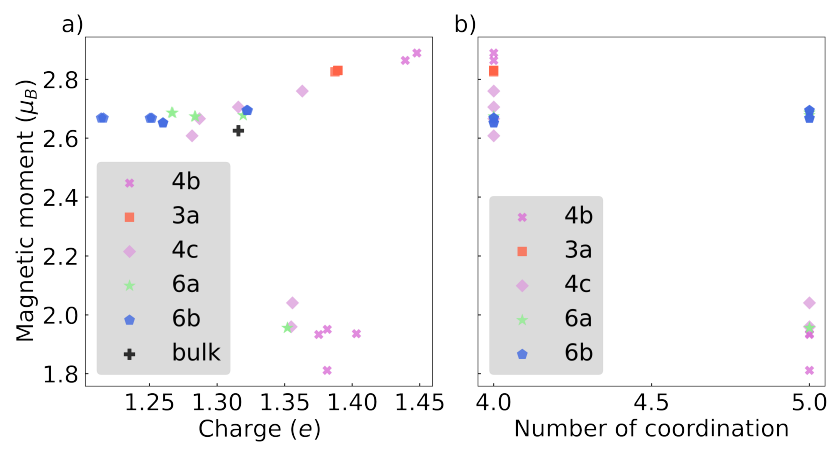

FIG. 11: Magnetic moment of the topmost metal atoms on the most stable $\mathrm{Co}_{3} \mathrm{O}_{4}(111)$ surfaces as a function of its charge and coordination.

in Figure 11. Two magnetic moments can be clearly distinguished. The state with a higher magnetic moment of approximately $2.7 \mu_{B}$, increases its value as the surface is increasingly oxidized and it is in accordance with an oxidation state of +2 and high spin configuration. The other magnetic moment observed is of around $1.9 \mu_{B}$, in agreement with the presence of $\mathrm{Co}^{3+}$ in an intermediate spin state. In general, the charge on the metal ions follows the degree of oxidation of the surfaces. Moreover the charge of the $\mathrm{Co}^{3+}$ ion is at least higher or equal to the charge of the same ion on the bulk: $+1.36 e$.

Unexpectedly, the oxidation state is not completely correlated with the charge but it is more in agreement with the coordination of the ion. Most of the $\mathrm{Co}^{2+}$ ions have a coordination number of 4 in a tetrahedral geometry whereas all of the metal ions in oxidation state +3 are penta-coordinated forming trigonal bipyramidal or square pyramidal structures. On the bulk oxide, where all the trivalent ions are octahedrally coordinated, the $\mathrm{Co}^{3+}$ is in the low state. As we mentioned before, the spin state of these ion is strongly dependent of the coordination geometry, being easily modified by temperature or pressure changes [61].

Some of the metal ions on system $\mathbf{6} \mathbf{b}$ have also a coordination number of 5 in a distorted square pyramidal geometry. However, in this case and because the amount of oxygen atoms is low, the charge on the ions is lower than $+1.35 e$ and they remain in oxidation state +2 . As it usual for many divalent ions, they are in a high spin state (with magnetic moment around $3 \mu_{B}$ ), even when the geometry of coordination is not anymore tetrahedral [62].

The system $\mathbf{3 a}$, that is the predominant surface in the Pourbaix diagrams, has the lowest amount of metal ions of the systems analyzed in this section. It is also the flattest surface with all its Co ion tetrahedrally coordinate in oxidation state +2 . In spite of the oxidation state, the ion charge of $+1.39 e$ is higher than the charge of $\mathrm{Co}^{3+}$ ion in the bulk. The position of the center of its d-band (shown in Figure 12) is more in agreement with the charge than with the oxidation state due to the magnetic moment.

The position of the d-band centers of the analyzed 

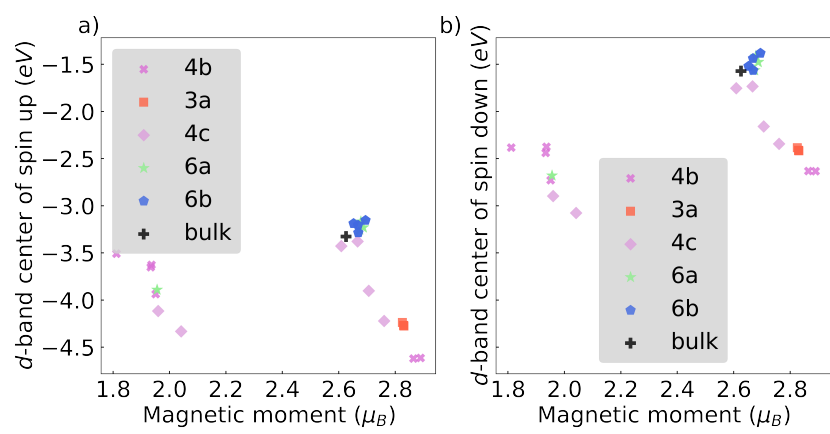

FIG. 12: Center of the d-band of the topmost metal atoms on the most stable (111) surfaces of $\mathrm{Co}_{3} \mathrm{O}_{4}$ as a function of its magnetic moment.

metal ions moves to more negative values as the charge on the ions increases and it becomes more oxidized. There are not significant differences between the values of the spin-up band of the oxidation states +2 and +3 , however the spin-down pDOS is closer to the Fermi level when the metal ions are more reduced.

The analysis of the Bader charges and magnetic moments have shown that in the most stable surface $(\mathbf{3 a})$ the metal ions are in an oxidation and spin states most likely to be inactive. In addition, it can be seen in Fig. 7 that the distance between the cobalt ions on the surface is too large to make possible the formation of $\mu$ oxo bridges. Nevertheless, there is another system that is close to the region of thermodynamic stability: surface 4c. Here again, Fig. 7 shows the presence of some $\mathrm{Co}^{3+}$ ion (green spheres) connected to neighbor cobalt ions through $\mu_{2}-\mathrm{OH}$ bonds. Both characteristics make metal ions on surface 4c promising active centers for OER/ORR catalysis.

Undoubtedly, surface termination $\mathbf{3 a}$ is thermodynamically more stable than system $\mathbf{4 c}$ in the experimental conditions simulated in this work, when the solvent is only included as a continuum polarizable medium. So we would predict that this surface termination should be present under operating conditions. However, experimental results have shown that the (111) surface of the $\mathrm{Co}_{3} \mathrm{O}_{4}$ oxide is an active OER/ORR catalysts because of the presence of $\mathrm{Co}^{3+}$ ions on the surface [23, 25, 63-69] and/or the formation of $\mu_{2}$-oxo bridges between adjacent metal ions $[28,30,70]$. However, because of the lack of those characteristics, system $\mathbf{3 a}$ is very likely to be inactive, so that it is not consistent with the experiments mentioned above that this system should be the thermodynamically most stable structure under operating conditions. This discrepancy might be a consequence of the lack of explicitly considered water molecules in our study [71]. Preliminary DFT calculations appear to confirm that system $\mathbf{4 c}$ becomes the most stable one when water molecules are included explicitly and forming the first solvation layer. Water molecules added to the surface will not only modify the stability of the surfaces but they will also change the charge of the metal ions and the acidity of the adsorbed $\mathrm{H}$ atoms. A change in the coordination number of the metallic can also modify the oxidation state having a significant impact on its oxidizing properties. The role of explicit water molecules for the structure and catalytic activity is the subject of a forthcoming study.

\section{CONCLUSION}

Cobalt and manganese oxides are promising materials for bifunctional catalyst for both the oxygen evolution as well as the oxygen reduction reaction. The thermodynamically stable phases of $\mathrm{Mn}_{3} \mathrm{O}_{4}$ and $\mathrm{Co}_{3} \mathrm{O}_{4}(111)$ surfaces have been systematically studied under operating conditions in a grand-canonical approach based on density functional theory calculations. These materials are promising candidates for bifunctional OER and ORR catalysts at the cathode of zinc-air batteries. By considering a broad variety of non-stochiometric surface terminations, we have derived phase diagrams both for gas phase and electrochemical conditions. Due to the complexity of the underlying spinel structures, no simple rules for the factors determining the stability of the surface structures can be derived. We find that stoichiometric surface terminations are among the stable structures, however, lowering the metal to oxygen ratio does not significantly modify the energies as this lowering is accompanied by the saturation of initially dangling bonds of the metal ions. By analysing the charge, coordination and magnetic moment of the metal atoms we identify possible surface terminations that could be catalytically active with respect to the oxygen evolution reaction. We find such structures which, however, do not belong to the thermodynamically stable phases which might be due to the neglect of the explicit consideration of water molecules in the first-principles total energy calculations.

\section{ACKNOWLEDGMENTS}

This research has been supported by the German Science Foundation (DFG) through through contract GR 1503/34-1 and by the Chinese Scholarship Council (CSC). The authors acknowledge computer time provided by the state of Baden-Württemberg through the bwHPC program and the German Research Foundation (DFG) through grant no INST 40/575-1 FUGG (JUSTUS II cluster). This work contributes to the research performed at CELEST (Center for Electrochemical Energy Storage Ulm-Karlsruhe). 
[1] J.-S. Lee, S. Tai Kim, R. Cao, N.-S. Choi, M. Liu, K. T. Lee, and J. Cho, Metal-air batteries with high energy density: Li-air versus Zn-air, Adv. Energy Mater. 1, 34 (2011).

[2] Z.-C. Yao, T. Tang, J.-S. Hu, and L.-J. Wan, Recent advances on nonprecious-metal-based bifunctional oxygen electrocatalysts for zinc-air batteries, Energy Fuels 35, 6380 (2021).

[3] P. Quaino, E. Colombo, F. Juarez, E. Santos, G. Belletti, A. Groß, and W. Schmickler, On the first step in zinc deposition - a case of nonlinear coupling with the solvent, Electrochem. Comm. 122, 106876 (2021).

[4] J. Zhang, Z. Zhao, Z. Xia, and L. Dai, A metal-free bifunctional electrocatalyst for oxygen reduction and oxygen evolution reactions, Nature Nano 10, 444 (2015).

[5] A. Aijaz, J. Masa, C. Rösler, W. Xia, P. Weide, A. J. R. Botz, R. A. Fischer, W. Schuhmann, and M. Muhler, $\mathrm{Co} @ \mathrm{Co}_{3} \mathrm{O}_{4}$ encapsulated in carbon nanotube-grafted nitrogen-doped carbon polyhedra as an advanced bifunctional oxygen electrode, Angew. Chem. Int. Ed. 55, 4087 (2016).

[6] H. Osgood, S. V. Devaguptapu, H. Xu, J. Cho, and $\mathrm{G}$. $\mathrm{Wu}$, Transition metal (Fe, $\mathrm{Co}, \mathrm{Ni}$, and $\mathrm{Mn}$ ) oxides for oxygen reduction and evolution bifunctional catalysts in alkaline media, Nano Today 11, 601 (2016).

[7] H. M. Amin, C. J. Bondue, S. Eswara, U. Kaiser, and H. Baltruschat, A carbon-free $\mathrm{Ag}-\mathrm{Co}_{3} \mathrm{O}_{4}$ composite as a bifunctional catalyst for oxygen reduction and evolution: Spectroscopic, microscopic and electrochemical characterization, Electrocatal. 8, 540 (2017).

[8] K. Elumeeva, J. Masa, D. Medina, E. Ventosa, S. Seisel, Y. U. Kayran, A. Genç, T. Bobrowski, P. Weide, J. Arbiol, M. Muhler, and W. Schuhmann, Cobalt boride modified with $\mathrm{N}$-doped carbon nanotubes as a high-performance bifunctional oxygen electrocatalyst, J. Mater. Chem. A 5, 21122 (2017).

[9] M. Qu, X. Ding, Z. Shen, M. Cui, F. E. Oropeza, G. Gorni, V. A. de la Pena O'Shea, W. Li, D.-C. Qi, and K. H. L. Zhang, Tailoring the electronic structures of the $\mathrm{La}_{2} \mathrm{NiMnO}_{6}$ double perovskite as efficient bifunctional oxygen electrocatalysis, Chem. Mater. 33, 2062 (2021).

[10] B. Yeo and A. Bell, Enhanced activity of gold-supported cobalt oxide for the electrochemical evolution of oxygen, J. Am. Chem. Soc. 133, 5587 (2011).

[11] F. Cheng, J. Shen, B. Peng, Y. Pan, Z. Tao, and J. Chen, Rapid room-temperature synthesis of nanocrystalline spinels as oxygen reduction and evolution electrocatalysts, Nat. Chem. 3, 79 (2011).

[12] Y. Liang, Y. Li, H. Wang, J. Zhou, J. Wang, T. Regier, and $\mathrm{H}$. Dai, $\mathrm{Co}_{3} \mathrm{O}_{4}$ nanocrystals on graphene as a synergistic catalyst for oxygen reduction reaction, Nat. Mater. 10, 780 (2011).

[13] M. Garcia-Mota, A. Vojvodic, H. Metiu, I. C. Man, H.-Y. Su, J. Rossmeisl, and J. K. Nørskov, Tailoring the activity for oxygen evolution electrocatalysis on rutile $\mathrm{TiO}_{2}(110)$ by transition-metal substitution, ChemCatChem 3, 1607 (2011).

[14] A. Saad, D. Liu, Y. Wu, Z. Song, Y. Li, T. Najam, K. Zong, P. Tsiakaras, and X. Cai, Ag nanoparticles modified crumpled borophene supported $\mathrm{Co}_{3} \mathrm{O}_{4}$ catalyst showing superior oxygen evolution reaction (OER) performance, Appl. Catal. B 298, 120529 (2021).

[15] L. Tian, X. Zhai, X. Wang, J. Li, and Z. Li, Advances in manganese-based oxides for oxygen evolution reaction, J. Mater. Chem. A 8, 14400 (2020).

[16] J. Melder, P. Bogdanoff, I. Zaharieva, S. Fiechter, H. Dau, and P. Kurz, Water-oxidation electrocatalysis by manganese oxides: Syntheses, electrode preparations, electrolytes and two fundamental questions, Z. Phys. Chem. 234, 925 (2020).

[17] C. P. Plaisance and R. A. van Santen, Structure sensitivity of the oxygen evolution reaction catalyzed by cobalt(II,III) oxide, J. Am. Chem. Soc. 137, 10.1021/jacs.5b07779 (2015).

[18] J. Simböck, M. Ghiasi, S. Schönebaum, U. Simon, F. M. F. de Groot, and R. Palkovits, Electronic parameters in cobalt-based perovskite-type oxides as descriptors for chemocatalytic reactions, Nat. Comm. 11, 1 (2020).

[19] J. Suntivich, K. J. May, H. A. Gasteiger, J. B. Goodenough, and Y. Shao-Horn, A perovskite oxide optimized for oxygen evolution catalysis from molecular orbital principles, Science 334, 1383 (2011).

[20] J. Huang, J. Chen, T. Yao, J. He, S. Jiang, Z. Sun, Q. Liu, W. Cheng, F. Hu, Y. Jiang, Z. Pan, and S. Wei, CoOOH nanosheets with high mass activity for water oxidation, Angew. Chem. Int. Ed. 54, 8722 (2015).

[21] J. Liu, H. Bao, B. Zhang, Q. Hua, M. Shang, J. Wang, and L. Jiang, Geometric occupancy and oxidation state requirements of cations in cobalt oxides for oxygen reduction reaction, ACS Appl. Mater. Interfaces 11, 12525 (2019).

[22] X. Wang, Y. Liu, T. Zhang, Y. Luo, Z. Lan, K. Zhang, J. Zuo, L. Jiang, and R. Wang, Geometrical-sitedependent catalytic activity of ordered mesoporous Cobased spinel for benzene oxidation: In situ DRIFTS study coupled with Raman and XAFS spectroscopy, ACS Catal. 7, 1626 (2017).

[23] Z. Chen, C. X. Kronawitter, and B. E. Koel, Facetdependent activity and stability of $\mathrm{Co}_{3} \mathrm{O}_{4}$ nanocrystals towards the oxygen evolution reaction, Phys. Chem. Chem. Phys. 17, 29387 (2015).

[24] Z. M. Chan, D. A. Kitchaev, J. N. Weker, C. Schnedermann, K. Lim, G. Ceder, W. Tumas, M. F. Toney, and D. G. Nocera, Electrochemical trapping of metastable $\mathrm{Mn}^{3+}$ ions for activation of $\mathrm{MnO}_{2}$ oxygen evolution catalysts, Proc. Natl. Acad. Sci. 115, E5261 (2018).

[25] D. Su, S. Dou, and G. Wang, Single crystalline $\mathrm{Co}_{3} \mathrm{O}_{4}$ nanocrystals exposed with different crystal planes for Li$\mathrm{O}_{2}$ batteries, Sci. Rep. 4, 5767 (2015).

[26] J. Huang, H. Sheng, R. D. Ross, J. Han, X. Wang, B. Song, and S. Jin, Modifying redox properties and local bonding of $\mathrm{Co}_{3} \mathrm{O}_{4}$ by $\mathrm{CeO}_{2}$ enhances oxygen evolution catalysis in acid, Nat. Comm. 12, 1 (2021).

[27] C. Hu, L. Zhang, Z.-J. Zhao, J. Luo, J. Shi, Z. Huang, and J. Gong, Edge sites with unsaturated coordination on core-shell $\mathrm{Mn}_{3} \mathrm{O}_{4} @ \mathrm{Mn}_{x} \mathrm{Co}_{3-x} \mathrm{O}_{4}$ nanostructures for electrocatalytic water oxidation, Adv. Mater. 29, 1701820 (2017).

[28] A. Bergmann, T. E. Jones, E. M. Moreno, D. Teschner, P. Chernev, M. Gliech, T. Reier, H. Dau, and P. Strasser, Unified structural motifs of the catalytically active state 
of co(oxyhydr)oxides during the electrochemical oxygen evolution reaction, Nature Catal. 1, 711 (2018).

[29] M. Risch, F. Ringleb, M. Kohlhoff, P. Bogdanoff, P. Chernev, I. Zaharieva, and H. Dau, Water oxidation by amorphous cobalt-based oxides: in situ tracking of redox transitions and mode of catalysis, Energy Environ. Sci. 8, 661 (2015).

[30] A. Bergmann, E. Martinez-Moreno, D. Teschner, P. Chernev, M. Gliech, J. F. de Araújo, T. Reier, H. Dau, and P. Strasser, Reversible amorphization and the catalytically active state of crystalline $\mathrm{Co}_{3} \mathrm{O}_{4}$ during oxygen evolution, Nat. Comm. 6, 8625 (2015).

[31] R. Frydendal, M. Busch, N. B. Halck, E. A. Paoli, P. Krtil, I. Chorkendorff, and J. Rossmeisl, Enhancing activity for the oxygen evolution reaction: The beneficial interaction of gold with manganese and cobalt oxides, ChemCatChem 7, 149 (2015).

[32] M. Garcia-Mota, M. Bajdich, V. Viswanathan, A. Vojvodic, A. T. Bell, and J. K. Nørskov, Importance of correlation in determining electrocatalytic oxygen evolution activity on cobalt oxides, J. Phys. Chem. C 116, 21077 (2012), https://doi.org/10.1021/jp306303y.

[33] A. Montoya and B. S. Haynes, Periodic density functional study of $\mathrm{Co}_{3} \mathrm{O}_{4}$ surfaces, Chem. Phys. Lett. 502, 63 (2011).

[34] F. Zasada, J. Gryboś, W. Piskorz, and Z. Sojka, Cobalt spinel (111) facets of various stoichiometry-DFT+U and ab initio thermodynamic investigations, J. Phys. Chem. C 122, 2866 (2018).

[35] K. Forster-Tonigold, J. Kim, J. Bansmann, A. Groß, and F. Buchner, Model studies on the formation of the solid electrolyte interphase: Reaction of $\mathrm{Li}$ with ultrathin adsorbed ionic-liquid films and $\mathrm{Co}_{3} \mathrm{O}_{4}(111)$ thin films, ChemPhysChem 22, 441 (2021).

[36] G. Yan and P. Sautet, Surface structure of $\mathrm{Co}_{3} \mathrm{O}_{4}(111)$ under reactive gas-phase environments, ACS Catal. 9, 6380 (2019).

[37] M. Li, S. Sakong, and A. Groß, In search of the active sites for the selective catalytic reduction on tungstendoped vanadia monolayer catalysts supported by $\mathrm{TiO}_{2}$, ACS Catal. 11, 7411 (2021).

[38] M. J. Eslamibidgoli, J. Huang, P. M. Kowalski, M. H. Eikerling, and A. Groß, Deprotonation and cation adsorption on the $\mathrm{NiOOH} /$ water interface: A grandcanonical first-principles investigation, Electrochim. Acta 398, 139253 (2021).

[39] A. Groß, Grand-canonical approaches to understand structures and processes at electrochemical interfaces from an atomistic perspective, Curr. Opin. Electrochem. 27, 100684 (2021).

[40] K. Reuter and M. Scheffler, Composition, structure, and stability of $\mathrm{RuO}_{2}$ (110) as a function of oxygen pressure, Phys. Rev. B 65, 035406 (2001).

[41] J. K. Nørskov, J. Rossmeisl, A. Logadottir, L. Lindqvist, J. R. Kitchin, T. Bligaard, and H. Jónsson, Origin of the overpotential for oxygen reduction at a fuel-cell cathode, J. Phys. Chem. B 108, 17886 (2004).

[42] G. Kresse and J. Furthmüller, Efficiency of ab-initio total energy calculations for metals and semiconductors using a plane-wave basis set, Comp. Mat. Sci. 6, 15 (1996).

[43] J. P. Perdew, K. Burke, and M. Ernzerhof, Generalized gradient approximation made simple, Phys. Rev. Lett. 77, 3865 (1996).
[44] S. Grimme, J. Antony, S. Ehrlich, and H. Krieg, A consistent and accurate ab initio parametrization of density functional dispersion correction (DFT-D) for the 94 elements H-Pu, J. Chem. Phys. 132, 154104 (2010).

[45] S. Grimme, S. Ehrlich, and L. Goerigk, Effect of the damping function in dispersion corrected density functional theory, J. Comp. Chem. 32, 1456 (2011).

[46] D. G. A. Smith, L. A. Burns, K. Patkowski, and C. D. Sherrill, Revised damping parameters for the d3 dispersion correction to density functional theory, J. Phys. Chem. Letters 7, 2197 (2016).

[47] P. E. Blöchl, Projector augmented-wave method, Phys. Rev. B 50, 17953 (1994).

[48] Z. Zeng, M. K. Y. Chan, Z.-J. Zhao, J. Kubal, D. Fan, and J. Greeley, Towards first principles-based prediction of highly accurate electrochemical Pourbaix diagrams, J. Phys. Chem. C 119, 18177 (2015).

[49] F. Buchner, K. Forster-Tonigold, J. Kim, J. Bansmann, A. Groß, and R. J. Behm, Interaction between li, ultrathin adsorbed ionic liquid films, and $\mathrm{CoO}(111)$ thin films: A model study of the solid - electrolyte interphase formation, Chem. Mater. 31, 10.1021/acs.chemmater.9b01253 (2019).

[50] R. A. Ribeiro, S. R. D. Lazaro, and S. A. Pianaro, Density functional theory applied to magnetic materials: $\mathrm{Mn}_{3} \mathrm{O}_{4}$ at different hybrid functionals, J. Magn. Magn. Mater. 391, 166 (2015).

[51] C. Franchini, R. Podloucky, J. Paier, M. Marsman, and G. Kresse, Ground-state properties of multivalent manganese oxides: Density functional and hybrid density functional calculations, Phys. Rev. B 75, 195128 (2007).

[52] S. A. Petrosyan, J.-F. Briere, D. Roundy, and T. A. Arias, Joint density-functional theory for electronic structure of solvated systems, Phys. Rev. B 75, 205105 (2007).

[53] S. Petrosyan, A. Rigos, and T. Arias, Joint densityfunctional theory: $\mathrm{Ab}$ initio study of $\mathrm{Cr}_{2} \mathrm{O}_{3}$ surface chemistry in solution, J. Phys. Chem. B 109, 15436 (2005).

[54] K. Letchworth-Weaver and T. A. Arias, Joint density functional theory of the electrode-electrolyte interface: Application to fixed electrode potentials, interfacial capacitances, and potentials of zero charge, Phys. Rev. B 86, 75140 (2012).

[55] W. Tang, E. Sanville, and G. Henkelman, A grid-based bader analysis algorithm without lattice bias, J. Phys.: Condens. Matter 21, 84204 (2009).

[56] A. Groß and S. Sakong, Modelling the electric double layer at electrode/electrolyte interfaces, Curr. Opin. Electrochem. 14, 1 (2019).

[57] F. Gossenberger, T. Roman, and A. Groß, Equilibrium coverage of halides on metal electrodes, Surf. Sci. 631, 17 (2015).

[58] F. Gossenberger, F. Juarez, and A. Groß, Sulfate, bisulfate, and hydrogen co-adsorption on $\mathrm{Pt}(111)$ and $\mathrm{Au}(111)$ in an electrochemical environment, Front. Chem. 8, 634 (2020).

[59] F. Gossenberger, T. Roman, and A. Groß, Hydrogen and halide co-adsorption on $\mathrm{Pt}(111)$ in an electrochemical environment: a computational perspective, Electrochim. Acta 216, 152 (2016).

[60] R. Arras, T. L. Le, S. Guillemet-Fritsch, P. Dufour, and C. Tenailleau, First-principles electronic structure calculations for the whole spinel oxide solid solution range 
$\mathrm{Mn}_{x} \mathrm{Co}_{3-x} \mathrm{O}_{4}(0 \leq x \leq 3)$ and their comparison with experimental data, Phys. Chem. Chem. Phys. 18, 26166 (2016).

[61] R. Y. Babkin, K. V. Lamonova, S. M. Orel, S. G. Ovchinnikov, and Y. G. Pashkevich, Temperature dependence of the spin state of a $\mathrm{Co}^{3+}$ ion in $\mathrm{RCoO}_{3}(\mathrm{R}=\mathrm{La}, \mathrm{Gd})$ cobaltites, JETP Letters 99, 476 (2014).

[62] P. Kumar, D. J. SantaLucia, K. Kaniewska-Laskowska, S. V. Lindeman, A. Ozarowski, J. Krzystek, M. Ozerov, J. Telser, J. F. Berry, and A. T. Fiedler, Probing the magnetic anisotropy of $\mathrm{Co}(\mathrm{II})$ complexes featuring redoxactive ligands, Inorg. Chem. 59, 16178 (2020).

[63] K. Song, E. Cho, and Y.-M. Kang, Morphology and active-site engineering for stable round-trip efficiency $\mathrm{Li}-$ $\mathrm{O}_{2}$ batteries: A search for the most active catalytic site in $\mathrm{Co}_{3} \mathrm{O}_{4}$, ACS Catalysis 5, 5116 (2015).

[64] J. Li, T. Hu, C. Wang, and C. Guo, Surface-mediated iron on porous cobalt oxide with high energy state for efficient water oxidation electrocatalysis, Green Energy Environ. https://doi.org/10.1016/j.gee.2020.11.009 (2020).

[65] X. Han, G. He, Y. He, J. Zhang, X. Zheng, L. Li, C. Zhong, W. Hu, Y. Deng, and T.-Y. Ma, Engineering catalytic active sites on cobalt oxide surface for enhanced oxygen electrocatalysis, Adv. Energy Mater. 8, 1702222 (2018).

[66] L. C. Schumacher, I. B. Holzhueter, I. R. Hill, and M. J. Dignam, Semiconducting and electrocatalytic properties of sputtered cobalt oxide films, Electrochim. Acta 35, 975 (1990).

[67] Y. Xu, F. Zhang, T. Sheng, T. Ye, D. Yi, Y. Yang, S. Liu, $\mathrm{X}$. Wang, and J. Yao, Clarifying the controversial catalytic active sites of $\mathrm{Co}_{3} \mathrm{O}_{4}$ for the oxygen evolution reaction, J. Mater. Chem. A 7, 23191 (2019).

[68] J. L. Gautier, E. Rios, M. Gracia, J. F. Marco, and J. R. Gancedo, Characterisation by x-ray photoelectron spectroscopy of thin $\mathrm{Mn}_{x} \mathrm{Co}_{3-x} \mathrm{O}_{4}(1 \geq \mathrm{x} \geq 0)$ spinel films prepared by low-temperature spray pyrolysis, Thin Solid Films 311, 51 (1997).

[69] E. Rios, P. Chartier, and J. L. Gautier, Oxygen evolution electrocatalysis in alkaline medium at thin $\mathrm{Mn}_{x} \mathrm{Co}_{3-x} \mathrm{O}_{4}$ $(1 \geq \mathrm{x} \geq 0)$ spinel films on glass $/ \mathrm{SnO}_{2}$ : $\mathrm{F}$ prepared by spray pyrolysis, Solid State Sci. 1, 267 (1999).

[70] F. Reikowski, F. Maroun, I. Pacheco, T. Wiegmann, P. Allongue, J. Stettner, and O. M. Magnussen, Operando surface x-ray diffraction studies of structurally defined $\mathrm{Co}_{3} \mathrm{O}_{4}$ and $\mathrm{CoOOH}$ thin films during oxygen evolution, ACS Catal. 9, 3811 (2019).

[71] Y. Gohda, S. Schnur, and A. Groß, Influence of water on elementary reaction steps in electrocatalysis, Faraday Discuss. 140, 233 (2008). 